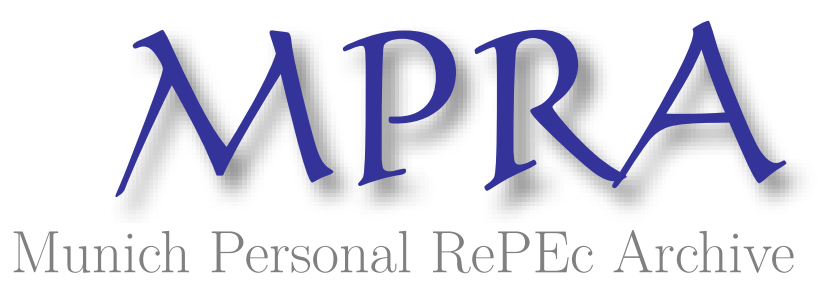

\title{
Reputation and Learning: Japanese Car Exports to the United States
}

Goksel, Turkmen

February 2011

Online at https://mpra.ub.uni-muenchen.de/40805/

MPRA Paper No. 40805, posted 22 Aug 2012 14:11 UTC 


\title{
Reputation and Learning: Japanese Car Exports to the United States*
}

\author{
John T. Dalton ${ }^{\dagger}$ \\ Turkmen Goksel ${ }^{\ddagger}$ \\ Wake Forest University \\ Ankara University
}

February 2011

\begin{abstract}
This paper incorporates learning and reputation building into a simple dynamic stochastic model of international trade with asymmetric information. We use the model to study a bilateral trade flow influenced significantly by learning and reputation, namely U.S. imports of Japanese cars over the period 1961-2005. Numerical simulations replicate the trade flow in a robust fashion. In addition to matching this event, we explore further implications of our framework for understanding international trade patterns. Since learning and reputation building require time, predicted short run trade patterns can be quite different than those predicted in the long run. Sectorial differences in the speed of learning and reputation building affect predicted trade patterns. The extent of asymmetric information existing between importers and exporters also changes under different trade policies.
\end{abstract}

JEL Classification: D82, D83, F10, F14

Keywords: international trade, reputation, learning, asymmetric information, automobile

${ }^{*}$ We are grateful to Tim Kehoe, Cristina Arellano, and Pedro Amaral for their support and advice. We also thank Tom Holmes, Tommy Leung, Terry Roe, Hakki Yazici, and the members of the Trade and Development workshop at the University of Minnesota for their suggestions and comments.

${ }^{\dagger}$ Contact: Department of Economics, Carswell Hall, Wake Forest University, Box 7505, Winston-Salem, NC 27109. Email: daltonjt@wfu.edu

${ }^{\ddagger}$ Contact: Department of Economics, Ankara University, TR-06590 Cebeci, Ankara, Turkey. Email: turkmen.goksel@politics.ankara.edu.tr 


\section{Introduction}

This paper studies how asymmetric information affects international trade patterns and how learning and building up a reputation may be crucial in reducing information problems in international trade. In the framework we develop, asymmetric information exists regarding producers' (exporters') characteristics. $^{1}$ Consumers (importers) cannot completely observe the characteristics of exporters and have imperfect information about them, whereas exporters fully know their own characteristics. These informational asymmetries create frictions in the business dealings between importers and exporters which inhibit the flow of goods internationally. Since learning (for importers) and reputation building (for exporters) requires time, we find predicted short run trade patterns can be quite different than those predicted in the long run. Our framework provides new tools for analyzing data on international trade flows. We apply these tools to the case of Japanese car exports to the U.S., finding that numerical simulations of our model are capable of replicating the trade flow in a robust fashion.

Since the publication of Akerlof (1970), it has been well understood how asymmetric information can cause adverse selection in markets. We argue asymmetric information problems are crucial in international markets, even more so than closed economies, since information regarding foreign exporters is potentially less available and more difficult to access. For instance, inspection of foreign exporters may be difficult and costly to undertake. As a result, asymmetric information problems about a foreign exporter's productivity or the quality of a foreign exporter's good can be more severe in international markets. Additional factors, such as culture, language, or religion, have further effects on international markets with informational asymmetries. These factors can either exacerbate the problem by building prejudices between groups who differ in these respects or alleviate it by networking geographically dispersed groups together who are similar in these respects. ${ }^{2}$

In environments with informational asymmetries, Spence (1973) demonstrates how signaling can improve the market outcome, and Shapiro (1983) shows how building up a reputation can be important as well. Similarly, in international markets, exporters can use signals to build their reputations and alleviate problems caused by asymmetric information. Falvey (1989) extends the framework used in Shapiro (1983) to study the effects of commercial trade policies, such as origin labelling requirements,

\footnotetext{
${ }^{1}$ In general, the characteristics we discuss here can be thought of as affecting the consumers' beliefs, such as producers' productivity, quality, reliability, etc. For simplicity, we later narrow our concept of characteristics to be just productivity in our model.

${ }^{2}$ See, for example, Guiso, Sapienza, and Zingales (2009) for a study involving a set of European Union countries on how culture effects trust between citizens of different countries and how these bilateral trust relations affect international trade, portfolio investment, and foreign direct investment. See Gould (1994), Greif (1989), and Rauch and Trindade (2002) for examples of ethnic-based networks as means to alleviate asymmetric information problems and facilitate international trade.
} 
in a world in which reputation matters.

In parallel to the above findings, we argue that all these concepts - asymmetric information, learning, signaling, and reputation building - are important in international trade and should be incorporated into models in the international trade literature. The international trade literature usually implicitly assumes perfect information among agents, and, hence, asymmetric information plays no role. ${ }^{3}$ Since the main goal of this paper is to emphasize the idea that reputation building and learning are important in determining trade patterns, we focus our attention on developing a simple mechanism which clearly shows the relation between these forces. Our model is not based on traditional trade theory models and excludes some features of standard models. In particular, we take trade incentives as given and then narrow our attention to how asymmetric information, reputation, and learning affect international trade. Future research can incorporate these ideas into existing trade models. We then apply our mechanism to the study of Japanese car exports to the U.S.. The results of our analysis suggest researchers should consider information dynamics when trying to understand international trade data.

The mechanism we propose works as follows: There are two types of agents, exporters and importers. Exporters have private information about their characteristics. Importers only have beliefs about these characteristics. Importers wish to exchange their endowments for the output produced by exporters. The importers make offers to exporters in exchange for shipments of exporters' goods. These offers are based on beliefs importers hold about exporters' characteristics. Importers' beliefs, in turn, depend on the export history of an exporter, that is, an exporter's reputation. Exporters choose to accept or reject the offer depending on its profitability and how acceptance may affect the exporters' reputations. Hence, exporters potentially have the chance to send signals to affect the beliefs of importers through their acceptance of an offer and their output performance. An exporter can either build up a good or bad history or reputation through their output performance. Importers learn about the characteristics of exporters after receiving and consuming the shipment of goods and update their beliefs accordingly. All importers share common information. Updated beliefs affect future decisions, because importers change their offers according to their updated beliefs. After learning about the exporters, if an importer undervalued (overvalued) their characteristics and shipments of goods previously, then the importer can raise (lower) the offers. The setup of our model draws heavily from features in Holmstrom (1999).

We use our model to study the experience of U.S. car imports from Japan over the years 1961-2005.

\footnotetext{
${ }^{3}$ See, however, Nieuwerburgh and Veldkamp (2009) for a recent treatment of asymmetric information and learning in the international finance literature.
} 
The evolution of this trading experience depends in part on asymmetric information, learning, and reputation. Very few Japanese cars were exported to the U.S. before the 1970's. Before that time, big American cars ruled the road. American consumers showed little interest in the lightweight compact cars slowly trickling into the American market from Asia. The oil crises of the 1970's changed all that, though, as Americans began to show an interest in the fuel efficient Japanese cars.

As American consumers learned more about the new Japanese cars, they discovered that not only were the Asian imports fuel efficient, but they were well-built and reliable vis- $a$-vis their American rivals. Japanese cars established a good reputation, as evidenced by such publications as Consumer Reports. Japanese car imports to the U.S. increased dramatically thereafter. In addition, Wojcik (2001) documents total sales of Japanese cars in the U.S. as increasing by 427\% over the years 1971-1990, while total new car sales increased by only 9\%. Total sales numbers for Japanese cars from 1971 to 1990 are primarily being driven by imports, since Japanese manufactures did not begin setting up factories in the U.S. until the mid-1980's.

In order to apply our model to the experience of U.S. imports of Japanese cars, we simulate our model numerically to generate sample model time series data. The model's parameters are chosen using two alternative procedures, one feeding the observed oil shocks into the model and one a maximum likelihood method. We compare the simulated model data with the actual time series data and find that the model does a good job of matching the actual data. We show the reliability of these results with a test of robustness. Our test consists of simulating the model 10000 times and calculating the average model time series. We then construct a confidence interval around this average by adding and subtracting two standard deviations measured from the 10000 simulations of model data. These bands convey the robustness of our results. After showing the capability of our model in capturing the Japanese car experience, we discuss further results from our model which highlight the effects of asymmetric information, learning, and reputation in international trade.

Even though the structure of our model differs from Melitz (2003), it predicts similar results, namely that firms engaged in exporting are relatively more productive. However, this is a long run result, which corresponds to the case when asymmetric information problems have been reduced. In our model, the reduction of asymmetric information problems occurs when importers' beliefs are similar to the actual characteristics of the firms. In this case, our model makes the same predictions as Melitz (2003). In the short run, however, when asymmetric information still exists between importers and exporters, the results of our model are different. A firm's ability to export depends not only on its characteristics but also on what importers believe about those characteristics. Hence, an important implication of models 
with asymmetric information is that short run trade patterns can be quite different from those seen in the long run. Consequently, this can affect things like government policies as well.

One could argue that the learning and reputation building process generating the transition from the short (high informational asymmetries) to long run (low informational asymmetries) trade patterns occurs quite quickly. This might be true for some sectors, such as foods and beverages, in which it is easier to obtain information and update beliefs. For other sectors, however, the speed of the learning and reputation building process is much slower. Shapiro (1983) cites the automobile industry as such a sector. Information regarding a particular car or car manufacture is revealed slowly over the course of the entire life of that car. Characteristics such as reliability can only be observed after long periods of time. Our model captures this sectorial difference in the speed of learning and reputation building with a parameter. We then show how our model's predicted trade patterns change with changes in this parameter.

We measure the extent of asymmetric information existing between importers and exporters in our model by identifying the relation between importers' beliefs and exporters' true characteristics. Tracking this relation over time allows us to show how the informational environment in which importers and exporters interact changes. The relation between importers' beliefs and exporters' true characteristics can be thought of as a policy variable, which can be affected through different channels. We show that the incorporation of trade barriers or export subsidies in our model effects this relation, alongside the effects on trade patterns. In the case of trade barriers, exporters find it more difficult to export, which draws out the learning and reputation building process. As a result, the length of time required to reduce asymmetric information increases compared to the free trade case with no export subsidy policy. Export subsides produce the opposite result. The learning and reputation process shortens, as exporters now find it easier to export with the aid of subsidies. It then follows that asymmetric information between importers and exporters decreases faster than the free trade case with no export subsidy policy.

The remainder of the paper is organized as follows: Section 2 describes the model in detail. In section 3, we use our model to evaluate the experience of U.S. car imports from Japan. In section 4, we discuss additional model results. Section 5 concludes. 


\section{Model}

In this section, we develop a dynamic stochastic model of international trade with asymmetric information. This model is not built upon a standard international trade model and excludes some features of these models, as mentioned in the introduction. Instead, our model focuses exclusively on how asymmetric information, reputation, and learning can be crucial in the international trade literature.

As discussed in the introduction, exporters build their reputations based on characteristics observed by importers. For example, we could model reputation based on expected quality or, as we prefer to do here, expected productivity. In the case of expected quality, we could fix the output produced by each exporter $i$, normalizing it to 1 for simplicity, and allow for different quality levels. Since importers do not know ex-ante which exporter produces higher quality goods, importers learn by making offers to all exporters. There is noise in the learning process, so importers only identify the exact quality level of each exporter in the limit. Hence, in the short run, importers make offers to every exporter in every period. Our model focuses on this transition, not the limit case. Given the representative importer does not have exact information about quality levels, importers make offers to each exporter $i$ according to their expectations for quality conditional on their information set. In this case, exporters choose the quality level to export in order to affect the importers' beliefs.

What we do in this model is an isomorphic version of the above. Instead of fixing the output level, we focus on a homogeneous good, normalizing the price to 1 . We then allow different levels of output for each exporter $i$. The importers' offers are determined by expected quantity. Exporters now choose their output level to affect the importers' beliefs instead of quality. Hence, our model captures the idea of reputation as being the ability to produce more of the same good per period. We do this for simplicity. In general, our idea of reputation captures not only productivity, but also characteristics like quality, reliability, etc.

\section{$2.1 \quad$ Environment}

Consider an economy with two countries, home and foreign. ${ }^{4}$ We are mainly interested in studying imports to the home country, so we divide our economy's agents into home country importers and foreign country exporters. We assume importers are on the long side of the market. For simplicity, the home country contains a continuum of identical risk-neutral importers, and the foreign country contains a finite number of risk-neutral exporters which operate independently of one another. Competition

\footnotetext{
${ }^{4}$ This two country model can easily be extended to the multi-country case.
} 
ensures that importers pay their full surplus when importing from an exporter. This market structure is commonly employed in simple reputation models. See, for example, Tadelis (1999).

Foreign country exporters produce and potentially export a homogeneous good, $y$, to the home country. In contrast, importers do not possess the technology to produce $y$. In each period, importers are endowed with $\omega$. Importers want to exchange their endowment, $\omega$, for good $y$. Since we are focusing on studying imports to the home country, domestic production is not modeled. ${ }^{5}$ In the case of the home country, this can be interpreted as there also being domestic production for goods similar to $y$, but not exactly the good $y$. Due to taste for variety, the home country also wants to consume good $y$. In the case of the foreign country, this can be interpreted as all the exporters producing for their domestic market with some getting the chance to export and some not. Lastly, the economy exists for an infinite number of discrete time periods indexed by $t=0,1, \ldots$

\subsection{Information Structure and Uncertainty}

The key feature of this model is asymmetric information between importers and exporters. Exporters, indexed by $i=1,2, \ldots, I$, have potentially different actual productivity levels, $\eta_{i}$. Productivity levels are assumed to be fixed over time, that is, at the beginning of time $t=0$, each exporter is assigned a productivity level, which they keep forever. These actual productivity levels are exporters' private information and are incompletely known by importers. Rather, importers hold prior beliefs, $\hat{\eta}_{i 0}$, about each exporter's actual productivity level, $\eta_{i}$. Importers' prior beliefs, $\hat{\eta}_{i 0}$, are assumed to be normally distributed with mean $\mu_{\hat{\eta}_{i 0}}$ and variance $\sigma_{\hat{\eta}_{i 0}}^{2}$. As time passes, learning about $\eta_{i}$ will occur through the observation of exporter $i$ 's output. This gives rise to endogenously determined posterior beliefs, which will affect the status of the exporters.

Importers cannot directly observe the productivity level of individual exporters due to idiosyncratic productivity shocks, $\epsilon_{i t}$. We assume that $\epsilon_{i t}$ is normally distributed with mean zero and variance $\sigma_{\epsilon}^{2}$. We also assume productivity shocks are i.i.d. across exporters and time. These productivity shocks, $\epsilon_{i t}$, along with an exporter's productivity level, $\eta_{i}$, determine exporter $i$ 's output, $y_{i t}$, at time $t$, which is given by the technology 6

$$
y_{i t}=\max \left\{\eta_{i}+\epsilon_{i t}, 0\right\}
$$

where each exporter $i$ knows the actual realization of $\epsilon_{i t}$ at the beginning of each period $t$, but importers

\footnotetext{
${ }^{5}$ Adding domestic production to our model will not change the qualitative nature of the results.

${ }^{6}$ We do not allow the case when $y_{i t}<0$. This restriction implies a negative productivity shock can at most reduce an exporter's output to zero.
} 
only know the distribution of $\epsilon_{i t}$. The exporters' production technology is assumed to be publicly known. Under the above specification of the productivity shocks' distribution, we refer to $\epsilon_{i t}<0$ as "bad" shocks and $\epsilon_{i t}>0$ as "good" shocks, since they decrease or increase an exporter's output respectively.

Importers cannot observe $\eta_{i}$ and $\epsilon_{i t}$ separately but can only observe the total output, $y_{i t}$, if the exporter ships goods to the home country. Importers update their beliefs according to the total output they observe being shipped by each exporter. Information about each exporter perfectly spreads among the importers. In the event that an exporter chooses not to ship any amount of the good, $y_{i t}$, in a given period, then importers do not change their beliefs about this exporter.

Exporters also experience idiosyncratic cost shocks, $u_{i t}$. We assume that $u_{i t}$ is normally distributed with mean zero and variance $\sigma_{u}^{2}$. The cost shocks are i.i.d. across exporters and time. Both exporters and importers know the distribution of $u_{i t}$, but only exporters observe the actual realization of $u_{i t}$ at the beginning of the period. The exporters' cost function is assumed to be publicly known:

$$
c_{i t}=\max \left\{f-u_{i t}, 0\right\}
$$

where $f$ is a fixed cost of exporting and is the same across exporters and time.

\subsection{Timing}

Figure 1 summarizes the timing within a period in the model. At time $t=0$, exporters know their $\eta_{i}$ 's. In addition to this information, at the beginning of each period, exporters see their productivity shocks, $\epsilon_{i t}$, and cost shocks, $u_{i t}$. After the realization of the productivity and cost shocks to each exporter, importers make offers, $\phi_{i t}$, to each exporter $i$ at time $t$ according to their beliefs in that period. ${ }^{7}$ The importers' offers, $\phi_{i t}$, are made from their total endowment, $\omega_{t}$. Given the offer and the realization of the productivity and cost shocks, an exporter decides either to accept or reject the offer. If an exporter chooses to accept the offer, then importers pay their offer, $\phi_{i t}$, to the exporter, and the exporter pays the cost of producing and exporting, $c_{i t}$, and ships the output, $y_{i t}$, to the home country. If an exporter chooses to reject the offer, then the exporter receives zero payment, and no cost is paid. Once the shipments of output arrive in the home country, importers update their beliefs based on the output received. Importers update their beliefs about those exporters who actually shipped goods and keep the same beliefs for those who did not ship goods.

\footnotetext{
${ }^{7}$ There is no renegotiation between importers and exporters in a given period. An interpretation of this assumption is that negotiation between firms engaged in international trade is costly and time consuming. Thus, renegotiation within a given period is prohibited.
} 


$\eta_{i}, \varepsilon_{i t}, u_{i t}$
known by
exporters

\subsection{Importers}

There is a continuum of risk-neutral importers of measure $M$ in the home country with importers indexed by $m$. Importers are endowed with $\omega_{t}$ in each period and wish to exchange their endowment for the homogeneous good, $y$. In each period, representative importer $m$ makes a list of offers with one offer for each exporter. The representative importer $m$ chooses how much to offer each exporter according to the beliefs at that period, $\hat{\eta}_{i t}$. The expected utility of importer $m$ at time $t$ for dealing with a particular exporter $i$ is given by

$$
U_{i t}^{m}=E_{t}\left[y_{i t}\right]-\phi_{i t}
$$

where $E_{t}[\cdot]$ denotes the expectations with respect to the importer's available information at the beginning of time $t$ and $\phi$ is the offer paid to the exporter. ${ }^{8}$

Under risk neutrality, the competitive market equilibrium implies the market offer for each exporter $i$ will be

$$
\phi_{i t}\left(\Omega_{i t}\right)=E\left[y_{i t} \mid \Omega_{i t}\right]=\mu_{\hat{\eta}_{i t}} \quad \forall i, t>0,
$$

where $\Omega_{i t}=\left\{y_{i}^{t-1}, \cdot\right\}$ and $y_{i}^{t-1}=\left\{y_{i 0}, \ldots, y_{i t-1}\right\} \forall i, t>0 .{ }^{9}$

$\Omega_{i t}$ denotes the information set available to importers about exporter $i$ at time $t$. The information

\footnotetext{
${ }^{8}$ An importer's total utility is given by $\sum_{i=1}^{I} U_{i t}^{m}$. We also assume $\sum_{i}^{I} \phi_{i t}=\omega_{t} \forall t$, which implies importers have an exactly sufficient amount of endowment in each period.

${ }^{9}$ At $t=0, \phi_{i 0}=\mu_{\hat{\eta}_{i 0}}$. Note that, because $E\left[\epsilon_{i t}\right]=0$, the productivity shocks, $\epsilon_{i t}$, do not influence the optimal offers made by importers. From now on, we simply denote the importer's information set about exporter $i$ as the history of output, $y_{i}^{t-1}$.
} 
set consists of the history of exporter $i$ 's output up to time $t, y_{i}^{t-1}$. Since importers update their beliefs according to exporter $i$ 's output each period, their information sets are also updated. Importers only update their information set for an exporter if that exporter decides to accept the offer and ship an amount of goods to the home country. If an exporter decides not to accept the offer and not ship any goods, then importers do not update their information set for that particular exporter. We choose to simplify importers' learning in this manner since there are multiple reasons why an exporter might reject the offer. This important point is discussed further in section 2.5. $\Omega_{i t}$ is always the same for all importers, as additional information received by representative importer $m$ in each period perfectly spreads among importers.

If an exporter accepts the offer and sends an amount of the good, $y_{i t}$, then learning on the part of the importers results in normally distributed posterior beliefs, $\hat{\eta}_{i t+1}$. The mean, $\mu_{\hat{\eta}_{i t+1}}$, and precision, $h_{\hat{\eta}_{i t+1}}$, of $\hat{\eta}_{i t+1}$ are given by ${ }^{10}$

$$
\mu_{\hat{\eta}_{i t+1}}=\frac{\mu_{\hat{\eta}_{i t}} h_{\hat{\eta}_{i t}}+y_{i t} h_{\epsilon}}{h_{\hat{\eta}_{i t}}+h_{\epsilon}} \text { and } h_{\hat{\eta}_{i t+1}}=h_{\hat{\eta}_{i t}}+h_{\epsilon}
$$

where $h$ 's denote precisions of the respective variables. If an exporter rejects the offer and does not send any goods, than importers will have the same beliefs next period:

$$
\mu_{\hat{\eta}_{i t+1}}=\mu_{\hat{\eta}_{i t}} \text { and } h_{\hat{\eta}_{i t+1}}=h_{\hat{\eta}_{i t}}
$$

We choose to use precisions in equation (5) and (6) to simplify the discussion of results in section 4.

\subsection{Exporters}

We formulate the exporter's problem recursively for expositional simplicity. ${ }^{11}$ At the beginning of a period, let $v(\mu, h, \epsilon, u)$ be the optimal value of the problem for an exporter with $(\mu, h, \epsilon, u) .{ }^{12} \mu$ refers to the mean of the importers' beliefs. By equation (4), it is clear that $\phi=\mu$. We could either use $\phi$ or $\mu$ as a state variable. $h$ refers to the precision of the importers' beliefs. $\epsilon$ and $u$ are the realized productivity and cost shocks at a given period. The set $(\mu, h, \epsilon, u)$ summarizes the state variables for an exporter.

Lemma 1 If an exporter chooses to accept, then $y=\eta+\epsilon$.

Proof: See Appendix A.

\footnotetext{
${ }^{10}$ This is a well-known learning formula resulting from the normality and independence assumptions. See, for instance, Holmstrom (1999).

${ }^{11}$ We also formulate the problem sequentially in appendix A.

${ }^{12}$ Note that WLOG we drop the $i$ 's.
} 
Using Lemma 1, an exporter only decides whether to accept or reject the offer made by importers. The Bellman equation is given by

$$
v(\mu, h, \epsilon, u)=\max \left\{\pi+\iint \beta v\left(\mu^{\prime}, h^{\prime}, \epsilon^{\prime}, u^{\prime}\right) d F\left(u^{\prime}\right) d G\left(\epsilon^{\prime}\right), \iint \beta v\left(\mu, h, \epsilon^{\prime}, u^{\prime}\right) d F\left(u^{\prime}\right) d G\left(\epsilon^{\prime}\right)\right\},
$$

subject to the constraints

$$
\begin{gathered}
\pi \geq 0, \\
\mu^{\prime}=\frac{h \mu+h_{\epsilon}(\eta+\epsilon)}{h+h_{\epsilon}}, \\
h^{\prime}=h+h_{\epsilon},
\end{gathered}
$$

where $\pi=\mu-f+u$. The fixed cost, $f$; actual productivity, $\eta$; and precision of the distribution of productivity shocks, $h_{\epsilon}$, are constant over time.

The maximization is over the two actions: (1) accept the offer or (2) reject the offer. The first term on the R.H.S. of equation (7) refers to the case of accepting. An exporter earns current profit, $\pi$, and begins the next period facing importers with updated beliefs, $\mu^{\prime}$ and $h^{\prime}$. The second term on the R.H.S. of equation (7) refers to the case of rejecting. An exporter earns zero profit today and faces importers with the same beliefs, $\mu$ and $h$, during the next period. Successive draws of $\epsilon$ and $u$ are independent. $F(u)$, the c.d.f. of $u$, and $G(\epsilon)$, the c.d.f. of $\epsilon$, are independent of each other. There is no returning to earlier options. Equation (8) shows the nonnegativity condition for $\pi$. Equations (9) and (10) show how $\mu$ and $h$ evolve over time.

Proposition 1: Given Lemma 1 and $(\mu, h, \epsilon, u)$, an exporter chooses

$$
\left\{\begin{array}{ll}
\text { Accept, } & \text { if } \pi \geq 0 \text { and } \epsilon \geq \underline{\epsilon}(\mu, \cdot) \\
\text { Reject, } & \text { otherwise }
\end{array} .\right.
$$

Proposition 2: $\underline{\epsilon}(\mu, \cdot)$ is decreasing in $\mu$.

Proofs: See appendix A.

Lemma 1 clearly shows that if an exporter satisfies the conditions for accepting, then in order to build a good reputation in the shortest amount of time or to hide its bad productivity as long as possible, an exporter ships all the goods produced in a given period of time.

Proposition 1 is one of the main results of this paper. It captures the strategic choices made by exporters concerned with how current decisions affect their reputations and, thus, future profits. 
Consider the case when exporters make positive profits at a given time. Exporters still have to decide whether to enter the market or not, because they not only care about their current profits but their reputations, which affect future profits. For instance, if the current realization of the productivity shock is sufficiently low such that accepting and shipping the goods, $y$, would affect the importers' beliefs in a negative way, then an exporter $i$ may not choose to send the good, despite earning current positive profits. An exporter must weigh the current profit gain versus the discounted expected loss from future profits resulting from a negative reputation. Clearly, if the latter is greater, then an exporter chooses to reject even in the case of positive profits. Hence, $\underline{\epsilon}$ is the productivity threshold level which equates the value of the discounted expected lifetime profit streams in the cases of accepting and rejecting.

An exporter may choose to reject an offer for multiple reasons: 1) the offer is too low relative to the fixed cost (rejection due to negative profits), 2) the exporter received a bad cost shock (rejection due to negative profits), and/or 3) the exporter received a bad productivity shock (rejection due to protecting reputation). Notice, however, importers have no way of exactly determining why an exporter rejects the offer. Given this fact, we assume the potentially negative effect of a rejection signal is normalized to 0 , as seen in equation (6). Hence, regardless of the reason, rejection implies importers' beliefs remain the same as in the previous period.

Proposition 2 shows that an increase in the mean of the beliefs, $\mu$, in a given period of time decreases the threshold productivity. This result is crucial for the decision of an exporter deciding whether to accept or reject. Intuitively, if an exporter has a better reputation, then it can withstand worse shocks. In other words, an exporter who already established a good name in the market can choose to accept and send the goods even with a lower productivity shock.

\section{The Case of U.S. Car Imports from Japan}

In the above analysis, we introduced a mechanism stressing the importance of asymmetric information, learning, and reputation in international trade. We now use our model to study a bilateral trade flow, namely U.S. imports of Japanese passenger cars over the period 1961-2005. We choose to study this particular trade flow for two reasons. First, the automobile sector is a large and important sector in international trade. In the case of U.S. imports, passenger cars accounted for as much as $12.5 \%$ of total imports over the period 1961-2005. Second, asymmetric information, reputation, and learning occupy a leading role in explaining the evolution of Japanese car exports to the U.S. market. This claim is supported by a number of authors, both in the economics literature (see Mannering and Winston 
(1991), Train and Winston (2007), and Wojcik (2001)) and in the popular press (see Crandall and Winston (2005) and Gertner (2007)).

\subsection{Japanese Simulations}

Figure 2 shows U.S. passenger car imports from Japan over the period 1961-2005 from the OECD's International Trade by Commodity Database. Very few Japanese cars were exported to the U.S. before the 1970's. At the time, American consumers showed little interest in the lightweight compact cars coming from Japan, preferring instead the larger models produced by GM, Ford, and Chrysler, the so-called Big Three of automobile production. During the oil crises of 1973 and 1979, though, American consumers began to show an interest in the fuel efficient Japanese cars. As consumers learned more about the new Japanese cars, they discovered not only were the cars fuel efficient, but they were also well-built and reliable vis-à-vis their American rivals. Wojcik (2001) studies American consumer learning about a particular model, manufacturer, or Japanese cars in general during the 1970's, the period of the oil crises, and the 1980's. Wojcik (2001) uses a data set in which approximately $9 \%$ of households buy new cars each year. The share of new cars accounted for by Japanese imports increases from $5.7 \%$ in 1971 to $26.1 \%$ in 1990 , averaging $15.4 \%$ over the entire period. Wojcik (2001) finds all three sources of learning impacted the demand for individual Japanese cars in the American market and were significant factors in the increase in overall Japanese market share.

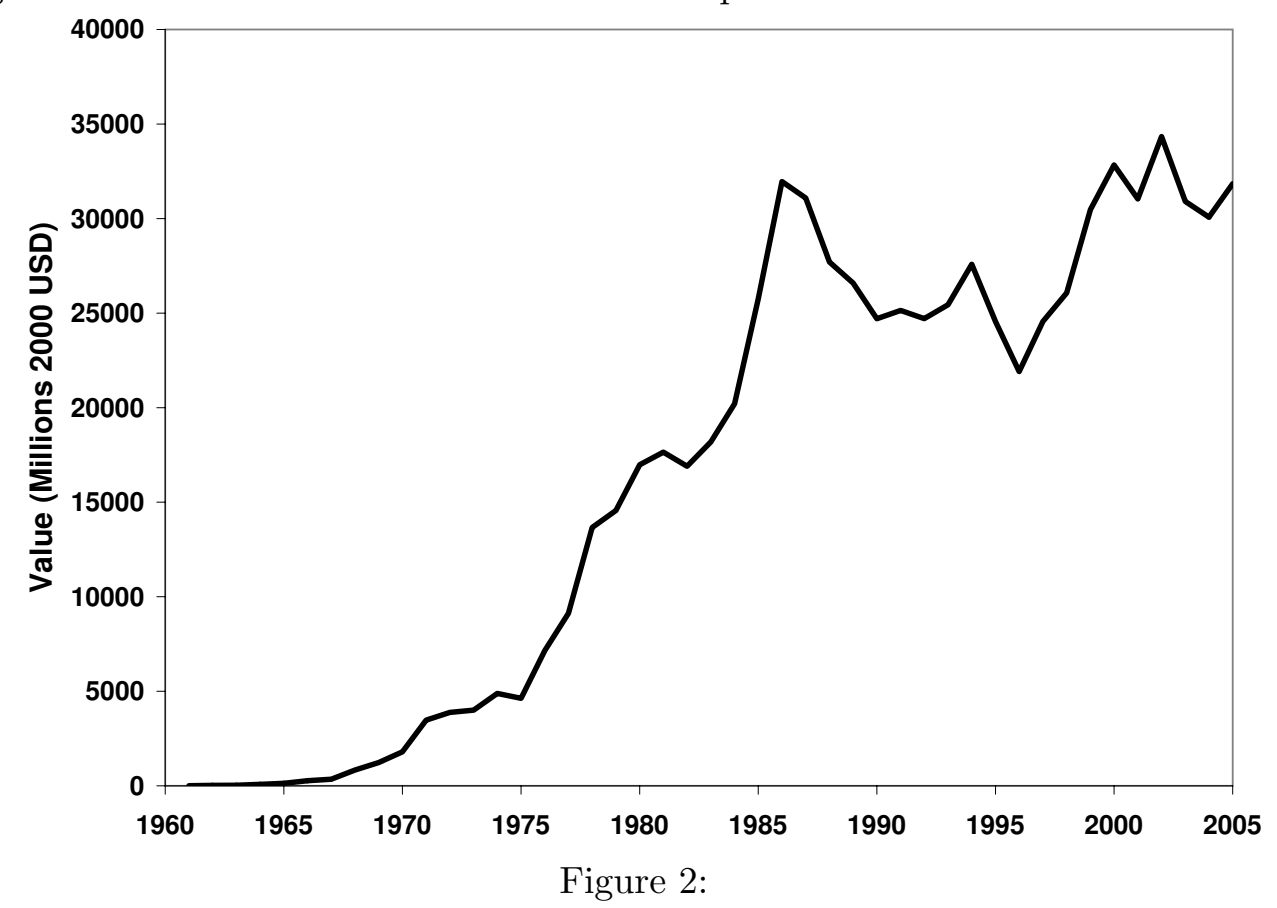

U.S. Imports of Japanese Passenger Cars 
The oil crises of the 1970's gave the Japanese exporters the opportunity to signal to American consumers about their cars and begin the process of building a reputation. In the years since the oil crises, the reputation of Japanese cars consistently ranked among the highest in the automobile industry, as publications like Consumer Reports clearly attest. Mannering and Winston (1991) documents that consumer brand loyalty, one potential measure of reputation, towards Japanese produced cars relative to American produced cars grew during the years after the oil crises. Mannering and Winston (1991) shows this brand loyalty explains a significant fraction of the increase in Japanese market share in the 1980's American automobile market. Through this signaling and learning process, U.S. car imports from Japan increased dramatically after 1975, as shown in figure 2. In addition, Wojcik (2001) documents total sales of Japanese cars in the U.S. as increasing by $427 \%$ over the years 1971-1990, while total new car sales increased by only $9 \%$. Total sales numbers for Japanese cars from 1971 to 1990 are primarily being driven by imports, since Japanese manufactures did not begin setting up factories in the U.S. until the mid-1980's.

In the language of our model, Japanese exporter $i$ 's actual productivity level, $\eta_{i}$, is high. However, Japanese exporters face American importers with such low prior beliefs, $\hat{\eta}_{i 0}$, and thus such low offers, in the years before the oil crises that Japanese exporters choose not to export. Eventually, the Japanese exporters in the model face cost shocks good enough such that they are able to export. We interpret the good cost shocks as the oil crises and a means by which Japanese exporters are able to signal to American importers about themselves, despite initially being faced with unfavorable beliefs on the part of American importers. Once American importers receive and consume a shipment of exporter $i$ 's goods, they update their beliefs, which affects future decisions made by the Japanese exporters. In this way, Japanese exporters eventually enter the American market and continue to export thereafter.

In order to run simulations to compare the model with the data, we first choose parameters for the case of Japan. Data used in determining the parameters of the model are collected from the OECD's International Trade by Commodity Database, the Japan Automobile Manufacturers Association, and corporate websites of individual Japanese manufacturers.

There are two crucial relations for these simulations. The first relation is between the actual productivity level, $\eta$, and the mean of the initial prior beliefs, $\mu_{\hat{\eta}_{0}}$ :

$$
\eta=\mu_{\hat{\eta}_{0}}+\theta_{1}
$$

where $\theta_{1} \in R . \theta_{1}>0(<0)$ corresponds to the case where the importers undervalue (overvalue) exporters. $\theta_{1}=0$ corresponds the case with no informational asymmetries. 
The second crucial relation is between the mean of the initial prior belief, $\mu_{\hat{\eta}_{0}}$, and the mean of the initial ex-ante cost distribution, $\mu_{c}$ :

$$
\mu_{\hat{\eta}_{0}}=\mu_{c}+\theta_{2}
$$

where $\theta_{2} \in R$. We refer to the cost distribution before the realization of $u_{i t}$ as the ex-ante cost distribution. Note that given the distribution of the cost shocks, the initial ex-ante cost distribution will be normally distributed with mean $f$ and variance $\sigma_{u}^{2}\left(=\sigma_{c}^{2}\right)$. For simplicity, we set the variances of the productivity shocks, $\sigma_{\epsilon}^{2}$; cost shocks, $\sigma_{u}^{2}$; and initial prior beliefs, $\sigma_{\hat{\eta}_{0}}^{2}$, equal to one another and denote them by $\sigma^{2}$ for both simulations. The more negative (positive) $\theta_{2}$ is, the lower (higher) is the probability of getting an initial offer greater than cost and, thus, having the chance to enter the market. For the simulations, we set $\eta_{i}=\eta$.

For the Japanese case, in order to identify $\theta_{1}$ and $\theta_{2}$, we first use the average of the last 15 data of U.S. imports of Japanese cars to identify $\eta: \eta=\frac{\text { Avg. } y_{\text {data }} \text { of } 91-05}{I}$, where $I=9$ is the number of Japanese exporters seen in the data. Given that importers initially undervalue the Japanese cars such that there are almost no imports before the oil crises, we have $\theta_{1}>0$ and $\theta_{2}<0$. We set $\theta_{1}=10 \sigma$ in order to capture the dramatic difference between the prior beliefs and the actual productivity of Japanese exporters. We set $\theta_{2}=-3 \sigma$ to capture the fact that there were almost no imports before the oil crises. $\epsilon$ and $u$ are randomly chosen variables in the simulation. However, for the years during the oil crises, the costs shocks are chosen to reflect the positive effect of the oil crises for Japanese exporters. We treat the cost shocks as random variables in the simulation before and after the oil crises.

Since $\sigma_{\epsilon}^{2}=\sigma_{\hat{\eta}_{0}}^{2}=\sigma_{u}^{2}=\sigma^{2}$, which implies the variance of the initial ex-ante cost distribution, $\sigma_{c}^{2}$, is also equal to $\sigma^{2}$, the choice of $\sigma$ is just a normalization. We set $\sigma$ equal to 200. Then, we calculate the exact values of $\theta_{1}$ and $\theta_{2}$. Given the values of $\theta_{1}, \theta_{2}$, and $\eta$, equations (12) and (13) pin down the values of $\mu_{\hat{\eta}_{0}}$ and $\mu_{c}$, i.e. $f$. We set $\beta=0.99$. Table 1 summarizes the parameters used in the Japanese simulations.

\begin{tabular}{llllllllll}
\hline \hline Parameter & $\eta$ & $\mu_{\hat{\eta}_{0}}$ & $\sigma$ & $\beta$ & $\mu_{\epsilon}$ & $\mu_{u}$ & $f$ & $T$ & $I$ \\
\hline Value & 3122 & 1122 & 200 & 0.99 & 0 & 0 & 1722 & 45 & 9 \\
\hline \hline
\end{tabular}

Table 1:

\section{Model Simulation: Parameters}

Figure 3 compares a sample trade flow simulation of our model,

$$
\sum_{i=1}^{I} y_{i t} \forall t
$$




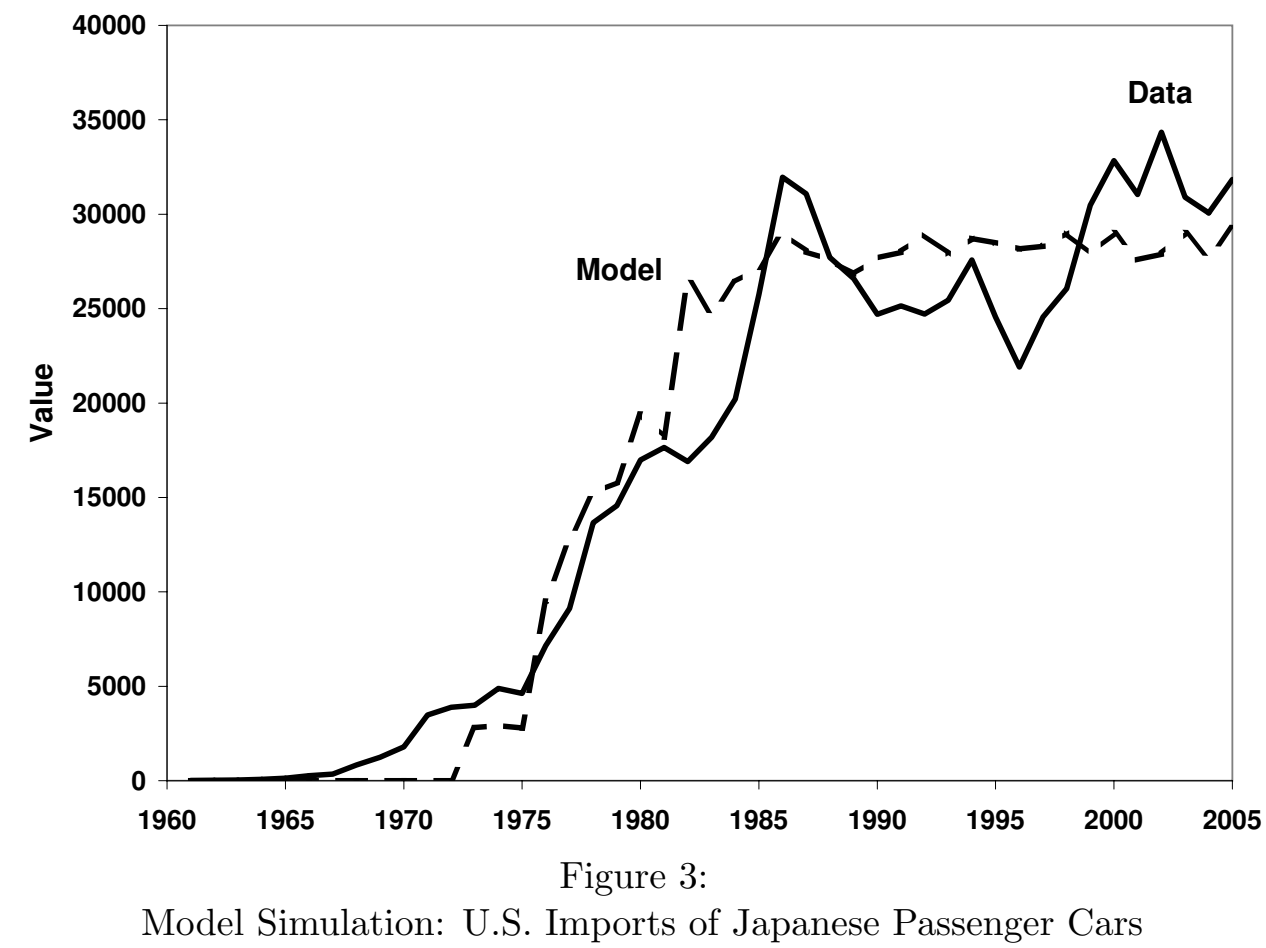

with the actual trade flow data on U.S. imports of Japanese cars over the years 1961-2005. The model replicates both the period of low imports before the 1970's oil crises and, once the oil crises occur, the subsequent years of increasing imports. All in all, figure 3 shows our model is capable of matching the data well.

However, figure 3 presents one sample trade flow simulation of our model. In order to test the reliability of this result, we construct a test of robustness. Figures 4 and 5 report our robustness results. These figures are constructed by repeating the simulation 10000 times. We then report the average of each year's 10000 simulation results. We also calculate the standard deviations for each year's 10000 simulation results and, then, add and subtract two standard deviations from each year's average to construct a confidence interval. These bands measure the robustness of our results.

As an additional test of robustness, we chose the parameters of the Japanese simulation using an alternative method which does not rely on choosing the cost shocks for a positive effect during the years of the oil crises. In order to find $\eta, \mu_{c}$, and $\mu_{\hat{\eta}_{0}}$, we first identify $\theta_{1}$ and $\theta_{2}$ by using a maximum likelihood method. We found $\theta$ 's such that firms were most likely to enter the market during the years of the oil crises. The likelihood function is as follows:

$$
L=\prod_{i=1}^{I^{\prime}}\left(\alpha_{1}^{\tau_{i}}\right)\left(1-\alpha_{1}\right)\left(1-\alpha_{i 2}\right) \ldots\left(1-\alpha_{i T-\tau_{i}}\right),
$$

where $I^{\prime}=$ number of actual exporters; $\alpha=$ probability of the cost being greater than the offer, i.e. 


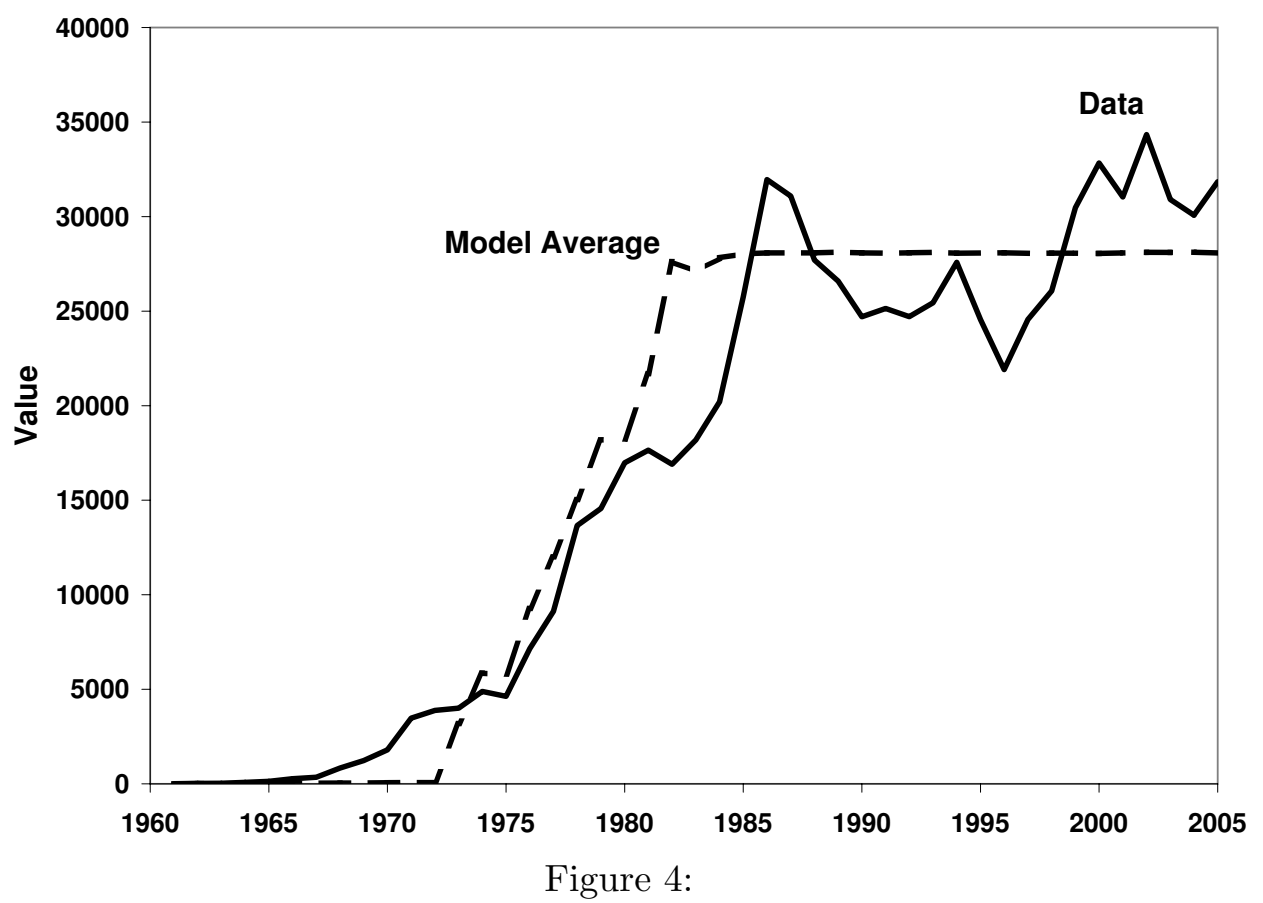

Model Simulation: Japanese Robustness

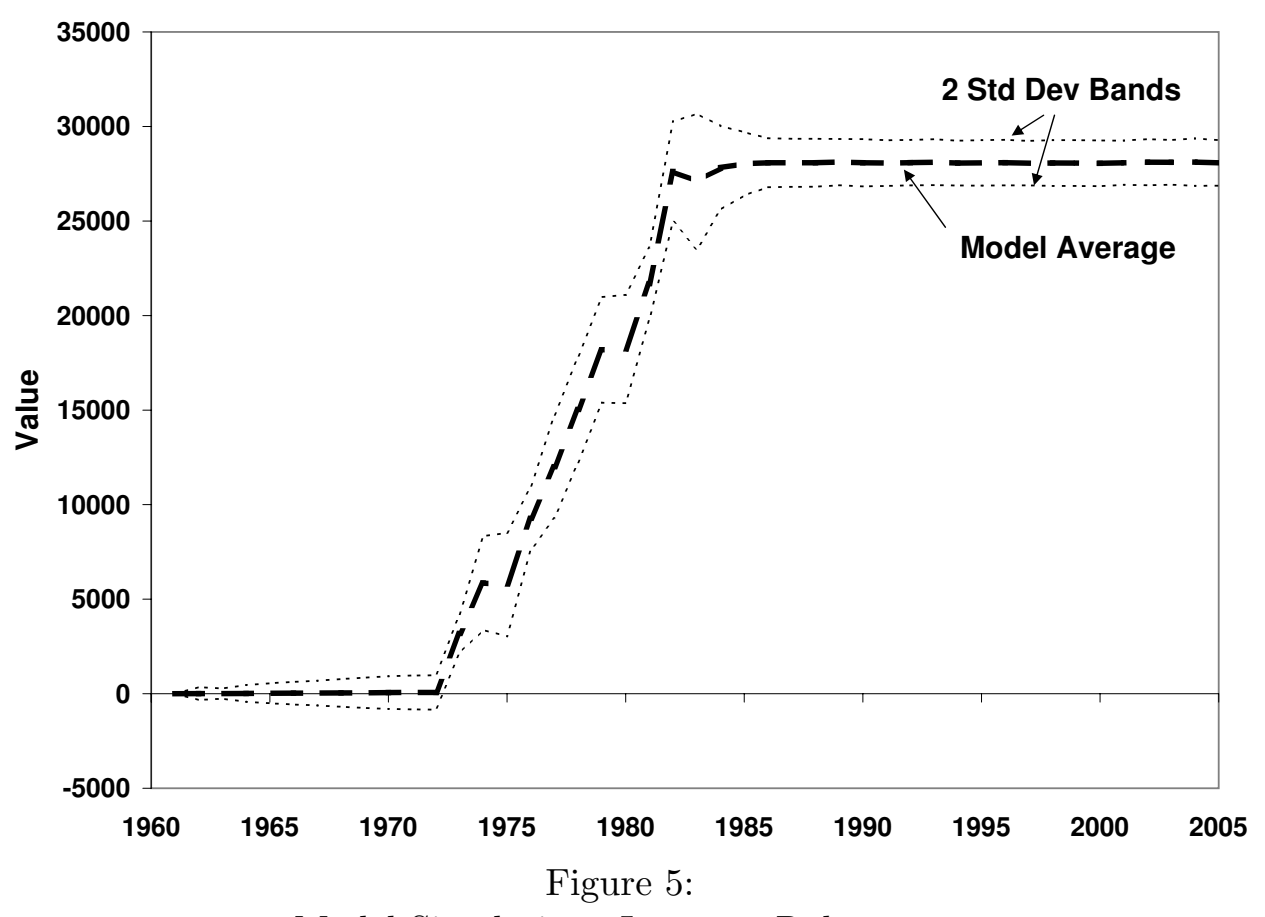

Model Simulation: Japanese Robustness 
not entering the market during a given period; $\tau_{i}=$ number of periods before exporter $i$ enters the market; and $T=$ total time periods. ${ }^{13}$ Note that $\alpha$ is the parameter in the likelihood function related to the parameters $\theta_{1}$ and $\theta_{2}$.

Intuitively, the first term in the likelihood function, $\alpha_{1}^{\tau_{i}}$, captures the first $\tau_{i}$ periods in which exporter $i$ is out of the market. Notice that this probability is not changing across exporters and periods until the first entrance into the market, because no updating has occurred yet. Since each exporter potentially enters the market in different periods, $i$ indexes $\tau$. The second term, $\left(1-\alpha_{1}\right)$, corresponds with the $(\tau+1)$ th period when an exporter enters the market for the first time. The other terms correspond to the case when once exporters enter the market, they always stay in, which captures the observed behavior of Japanese automobile firms. All the $\alpha^{\prime} s$, except $\alpha_{1}$, are potentially different for each period and each exporter due to the updating mechanism (5). $\theta_{2}$ closely relates to $\alpha_{1}$. All else equal, a high $\theta_{2}$ will increase the chance of entering the market, which corresponds to a low $\alpha_{1}$. $\theta_{1}$ relates to all $\alpha$ 's other than $\alpha_{1}$. All else equal, a high $\theta_{1}$ decreases the probability of not entering the market after the first entrance, which corresponds to the $\alpha$ 's other than $\alpha_{1}$ being low.

Given data collected on the entry dates of Japanese exporters into the American market, the $\tau$ for each exporter, we maximize the likelihood of not entering the market for $\tau$ periods, entry in the $(\tau+1)$ th period, and always being in the market thereafter for each exporter. Given each exporter's data, maximum likelihood returns the optimal $\alpha^{*}$ 's. We first identify the $\alpha^{\prime} s$, then find the corresponding values of the $\theta^{\prime}$ 's in terms of $\sigma$. Using the entry data, we find $\alpha_{1}^{*} \approx 0.98$, and clearly all other $\alpha^{*}$ 's are equal to zero. By using the solution to $\alpha_{1}^{*}$, the distance between $\mu_{\hat{\eta}_{0}}$ and $\mu_{c}$ must be $\approx 3 \cdot \sigma$, so we set $\theta_{2}=-3 \cdot \sigma$. The other $\alpha^{*}$ 's tell us the probability of not entering the market after the first entrance is zero. This implies that the posterior mean of the importers' beliefs should be sufficiently greater than the mean of the cost. By choosing $\theta_{1}=10 \cdot \sigma$, we virtually guarantee this will be the case. ${ }^{14}$

Since $\sigma_{\epsilon}^{2}=\sigma_{\hat{\eta}_{0}}^{2}=\sigma^{2}$, and as a result the variance of the initial ex-ante cost distribution is also equal to $\sigma^{2}$, the choice of $\sigma$ is just a normalization. Again, this simplification does not change our results. After finding the optimal $\alpha^{*}$ 's and corresponding $\theta$ 's in terms of $\sigma$, we set $\sigma$ equal to 200 . Then, we calculate the exact values of $\theta_{1}$ and $\theta_{2}$. We assume the $\eta$ 's are the same for the exporters and derive these from aggregate trade data. We set $\eta$ equal to the average of the last five data: $\eta=\frac{\text { Avg. } y_{\text {data }} \text { of } 00-05}{I^{\prime}}$.

The above procedure gives us $\theta_{1}, \theta_{2}$, and $\eta$. We use equation (12) to calculate $\mu_{\hat{\eta}_{0}}$. Using this

\footnotetext{
${ }^{13} I^{\prime}$ is taken from the data. We later identify the potential number of exporters, $I$, which we explain below in detail.

${ }^{14}$ Our choice of $\theta_{1}=10 \cdot \sigma$ makes the probability of not entering the market after the first entrance close, but not exactly equal, to zero.
} 
result and $\theta_{2}$, we calculate $\mu_{c}$, i.e. $f$, from equation (13). We choose $\beta=0.99$. We want the model's actual number of exporters, $I^{\prime}$, to be 9 , as in the actual data. Therefore, we use a maximum likelihood method to find the optimal number of potential exporters, $I$, most likely to generate $I^{\prime}=9$ :

$$
L=\left(\begin{array}{l}
I \\
9
\end{array}\right)(0.4082)^{I-9}(0.5918)^{9} .
$$

The first term denotes the choice of 9 exporters among the $I$ potential exporters. 0.4082 is the probability of not entering the market for 45 periods. ${ }^{15}(I-9)$ is the number of firms not entering the market for the entire 45 periods. 0.5918 is the probability of entering the market at some point during the 45 periods. Using this method, $I=15$. Table 2 summarizes the parameters obtained using the maximum likelihood method.

\begin{tabular}{llllllllll}
\hline \hline Parameter & $\eta$ & $\mu_{\hat{\eta}_{0}}$ & $\sigma$ & $\beta$ & $\mu_{\epsilon}$ & $\mu_{u}$ & $f$ & $T$ & $I$ \\
\hline Value & 3538 & 1538 & 200 & 0.99 & 0 & 0 & 2138 & 45 & 15 \\
\hline \hline
\end{tabular}

Table 2:

Model Simulation: Parameters, Maximum Likelihood Method

These alternative simulations generate similar results as those in figures 3,4 , and 5 , and we do not present them here.

The model's ability to match the data in figures 3,4 , and 5 depends crucially on two factors, the timing of the cost shocks and the learning, or reputation, process. In order to show the importance of these two factors, we conduct a number of experiments. ${ }^{16}$ The cost shocks in the model reflect the benefit of the oil crises for Japanese exporters. Keeping everything else in the simulations unchanged, it is clear that if the timing of these cost shocks changes, then the model is unable to match the data. However, the historical record suggests the oil crises were large and important shocks for the automobile industry, which motivates the choice of the timing of the cost shocks in our simulations. Any alternative theory attempting to explain the data on Japanese car exports must take seriously the impact of the oil crises.

Given the timing of the cost shocks coincides with the oil crises, we test how learning affects the model's ability to match the data. First, we analyze what happens when we turn off the learning mechanism in the model. Second, keeping the learning mechanism turned off, what happens if we add positive productivity shocks? Both of these experiments highlight the importance of learning and reputation as an explanation for the data versus alternative theories relying only on temporary shocks,

\footnotetext{
${ }^{15}$ This probability is derived using the distance between $\mu_{\hat{\eta}_{0}}$ and $\mu_{c}, \theta_{2}=-3 \cdot \sigma$

${ }^{16}$ We only provide discussion of these experiments here. The results are available upon request.
} 
such as productivity or exchange rate shocks.

Keeping everything else in the simulations unchanged, we turn off the learning mechanism by setting

$h_{\epsilon}$ close to 0 (see equation (5)). ${ }^{17}$ The model simulations cannot match the data when the learning mechanism is turned off. Once Japanese exporters receive the good cost shocks during the oil crises, they export to American importers. Americans do not update their beliefs about Japanese exporters, however, and continue to make low offers to Japanese exporters. Once the cost shock benefits end after the oil crises, Japanese exporters receive unprofitable offers and exit the American market. The model's simulated time series would consist of a positive spike in exports during the oil crises years and then an equivalent drop in exports once the crises end. As a result, temporary shocks without learning cannot generate a model time series consistent with the observed data.

As long as the learning mechanism is turned off, it does not matter if these shocks take the form of productivity shocks. We consider the case by adding positive productivity shocks to the simulations while keeping the learning mechanism turned off. The only difference than the previous case is that the temporary increase in exports during the oil crises is now greater due to the additional boost from the positive productivity shocks. But, again, American importers do not learn about Japanese exporters and, thus, continue to make low offers to the Japanese. Japanese exporters eventually exit the market once the benefits from the oil crises subside. These exercises show the importance of the timing of the cost shocks and the learning process in generating simulated model data consistent with the observed real data.

\section{Additional General Results}

In order to analyze the impact of asymmetric information, learning, and reputation on international trade patterns, we show the importance of differentiating between the short run and long run. This differentiation is crucial in terms of understanding trade patterns seen in the data and the implications of trade policies, such as import tariffs and export subsidies, in a world characterized by asymmetric information. We organize all the results in this section around numerical simulations of the model, the details of which are described in appendix B.

\footnotetext{
${ }^{17}$ We do not set $h_{\epsilon}$ exactly equal to 0 since the variance would be infinite.
} 


\subsection{Short Run vs. Long Run}

As in closed economies, asymmetric information can cause adverse selection problems in international markets in the short run. As time passes, a reduced information problem can be a solution to adverse selection. In the context of our model, any additional information achieved by the signals from exporters will aid importers in their learning process and help importers to update their information sets.

In the long run, importers' beliefs converge to the actual values of each exporter's productivity, $\eta_{i}$. This implies $\eta_{i}$ will be fully known in the limit. As a result, in the long run, relatively more productive exporters end up with larger amounts of exports. Relatively less productive exporters will still export but in relatively smaller amounts. A subset of these relatively less productive exporters will end up not exporting at all. These long run results are not different from existing trade literature and match those of Melitz (2003). However, in the short run these trade patterns can be potentially different.

In order to better understand this result, consider an example in which there are two types of exporters: exporters of type $\eta^{H}$ have high productivity, and those of type $\eta^{L}$ have low productivity. There are potentially many exporters of each type. Exporter $\eta^{H}$ is relatively more productive than exporter $\eta^{L}$, but this may not be true in terms of beliefs. Suppose at time $t=0$ the imperfect information is such that importers believe exporters of type $\eta^{L}$ are relatively more productive than $\eta^{H}$.

Given these conditions, the model predicts the trade flows depicted in figure 6. Exporters of type $\eta^{L}$ start with exporting a relatively higher amount due to the importers' beliefs, which result in higher offers. But, as time passes, the amount of type $\eta^{L}$ 's exports decreases. This occurs through importers learning about the actual productivity of exporters of type $\eta^{L}$, which in turn decreases the offers for these exporters. At the same time that the exports by type $\eta^{L}$ are decreasing, the exports by type $\eta^{H}$ are increasing due to a similar learning and reputation building mechanism. Once importers are able to learn about exporters of type $\eta^{H}$, the offers made to these exporters increase. As a result of these two effects, the trade patterns switch over time. Figure 6 shows the exporters of both types converging to a long run pattern, but the transition to these long run patterns, that is, the short run trade patterns, can be dramatically different due to asymmetric information, leading to an adverse selection problem. In the short run, importers are largely importing from exporters of type $\eta^{L}$, instead of $\eta^{H}$. Over

time, though, this adverse selection problem is solved. Signals by $\eta^{H}$ exporters reveal more and more information, and type $\eta^{H}$ exporters build a stronger reputation. Eventually, goods from exporters of type $\eta^{H}$ dominate the trade flows.

We can use this result to further our discussion of U.S. imports of Japanese Cars. Since this paper 


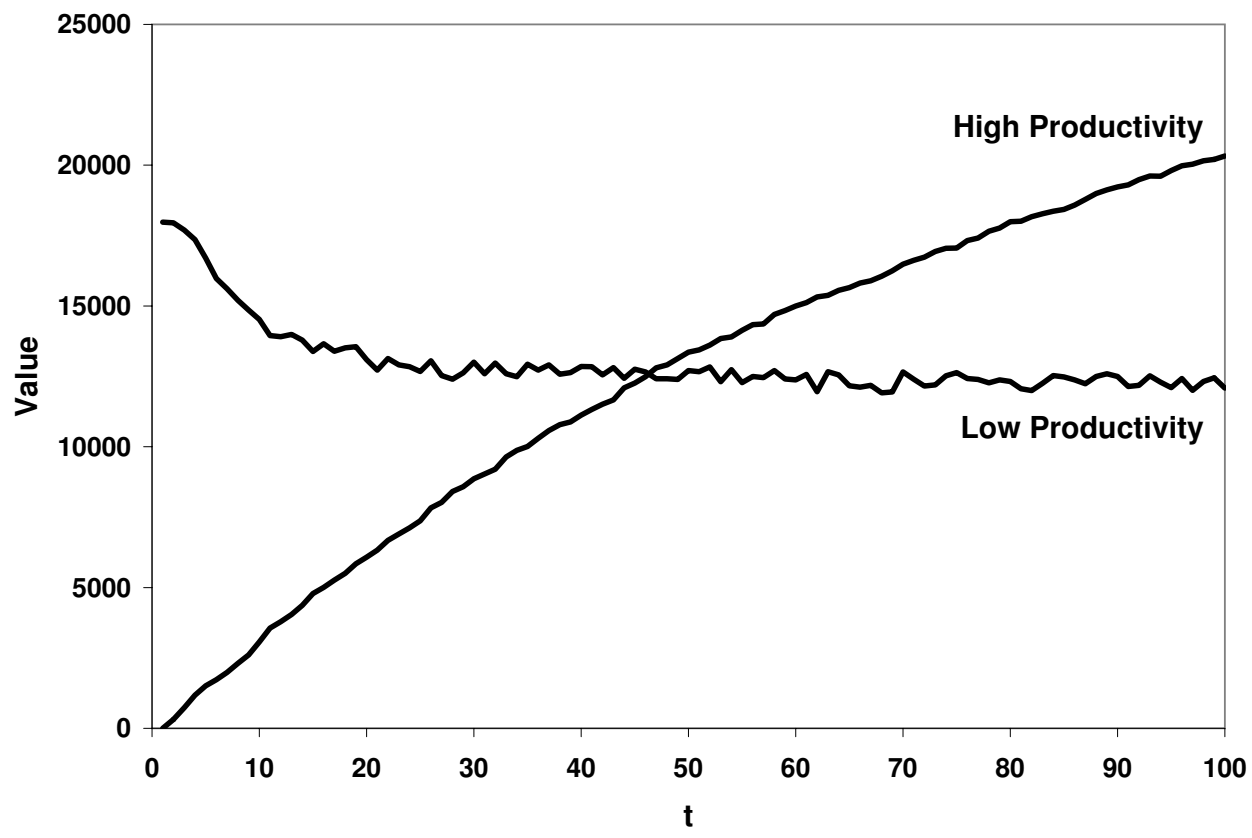

Figure 6:

Model Simulation: Total Exports, High vs. Low Productivity

develops a model of international trade, it is natural to study a significant bilateral trade relationship. The other side of the story about U.S. imports of Japanese cars is, of course, the oft-lamented decline in the competitiveness of the American automobile industry. The same Consumer Reports documenting the positive reputation of most Japanese cars documents the negative reputation of many American cars. The gap between American consumers' beliefs about Japanese and American cars is not improving. Indeed, Crandall and Winston (2005) compares annual issues of Consumer Reports in 1985 and 2005 suggesting this fact. In 1985, American consumers who purchased American cars were six times more likely to need "worse than average" or "much worse than average" car repairs than those consumers owning Japanese cars. American cars were still five times more likely than Japanese cars to need major repairs in 2005.

Reputation and consumer beliefs have their consequences. Figure 7 presents data taken from Train and Winston (2007) on American and Japanese market share of car sales in the U.S.. ${ }^{18}$ In the context of the model, if we consider American and Japanese manufactures as exporters trying to sell to importers, or American consumers, then the above result helps to understand figure 7. Notice the relation between figures 6 and 7. Recall figure 6 shows total exports of low and high productivity exporters. Importers' beliefs are such that low productivity firms dominate the market initially and only later do high productivity firms enter the market and eventually dominate. With American manufactures being the

\footnotetext{
${ }^{18}$ We only include American and Japanese manufacturers. As a result, the shares do not sum to 100.
} 


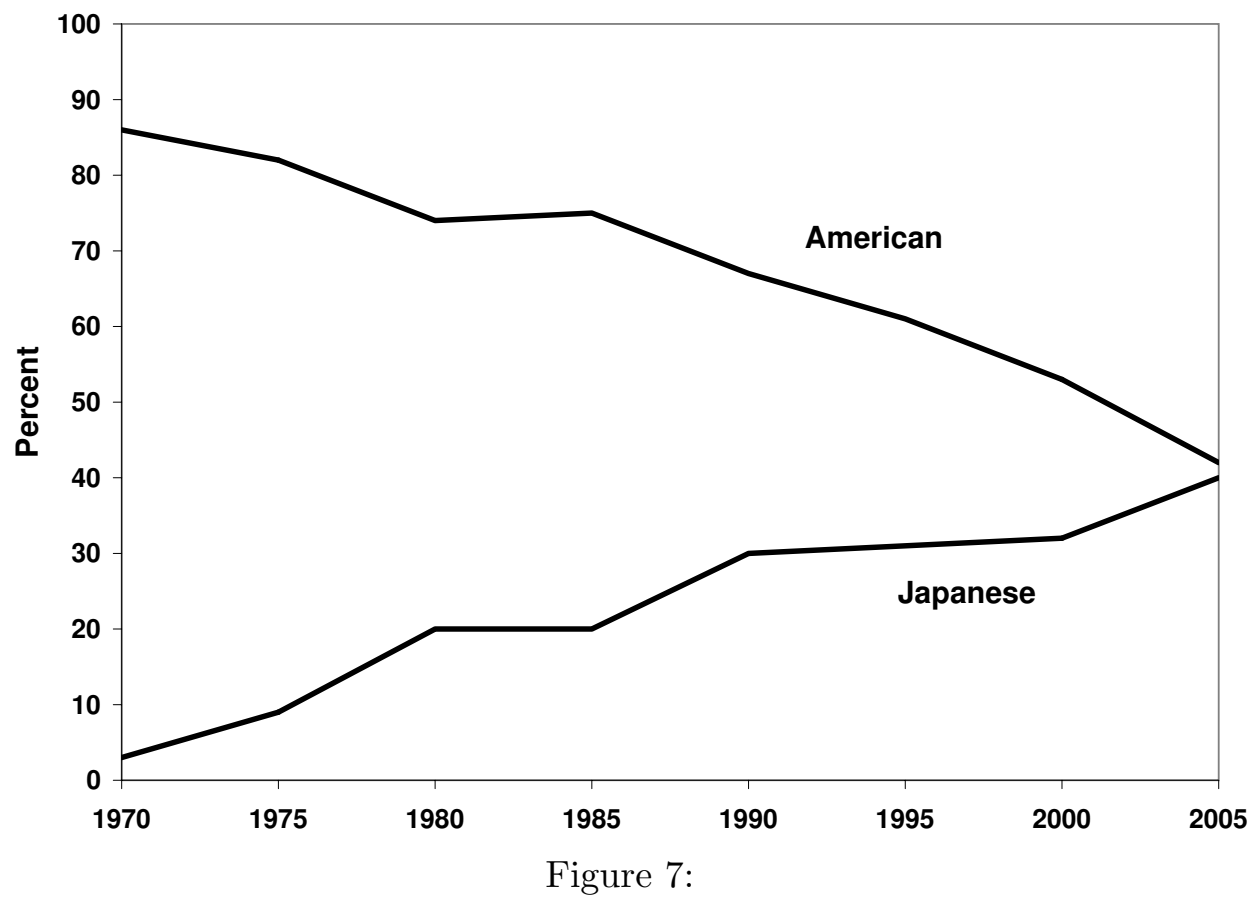

American and Japanese Market Share of Car Sales in the U.S.

low productivity firms and Japanese manufactures being the high productivity firms, figure 6 provides a possible explanation for figure 7. Although figure 7 shows Japanese market share in 2005 as still being $2 \%$ lower than American, it seems almost certain that the "switching" in relative positions seen in figure 6 will occur, especially in light of such news as Toyota overtaking General Motors as the largest car manufacturer for the first time in 2007. ${ }^{19}$ A similar switching has already occurred in the market shares of total vehicle sales in the U.S., as the share of vehicle sales due to non-American vehicles passed the share due to American for the first time in history in 2008. Whatever the future holds for American car manufacturers, our model suggests influencing consumers' beliefs by rebuilding a good reputation will be necessary if the trends seen in figure 7 are to be reversed.

\subsection{Speed of Learning and Reputation Building}

The learning and reputation process in our model depends on how the importers' beliefs evolve over time. As a result, the manner in which the beliefs change will influence the trade patterns predicted by the model. How the importers' beliefs evolve depends on the nature of the good being exported. Different sectors are associated with different learning and reputation processes. For example, Shapiro (1983) points out that beliefs about cars change only slowly. Consumers do not completely change their beliefs about a car manufacture after one period. The consumers partially adjust their beliefs, giving

\footnotetext{
${ }^{19}$ See Bradsher (2007) for reporting on this event.
} 


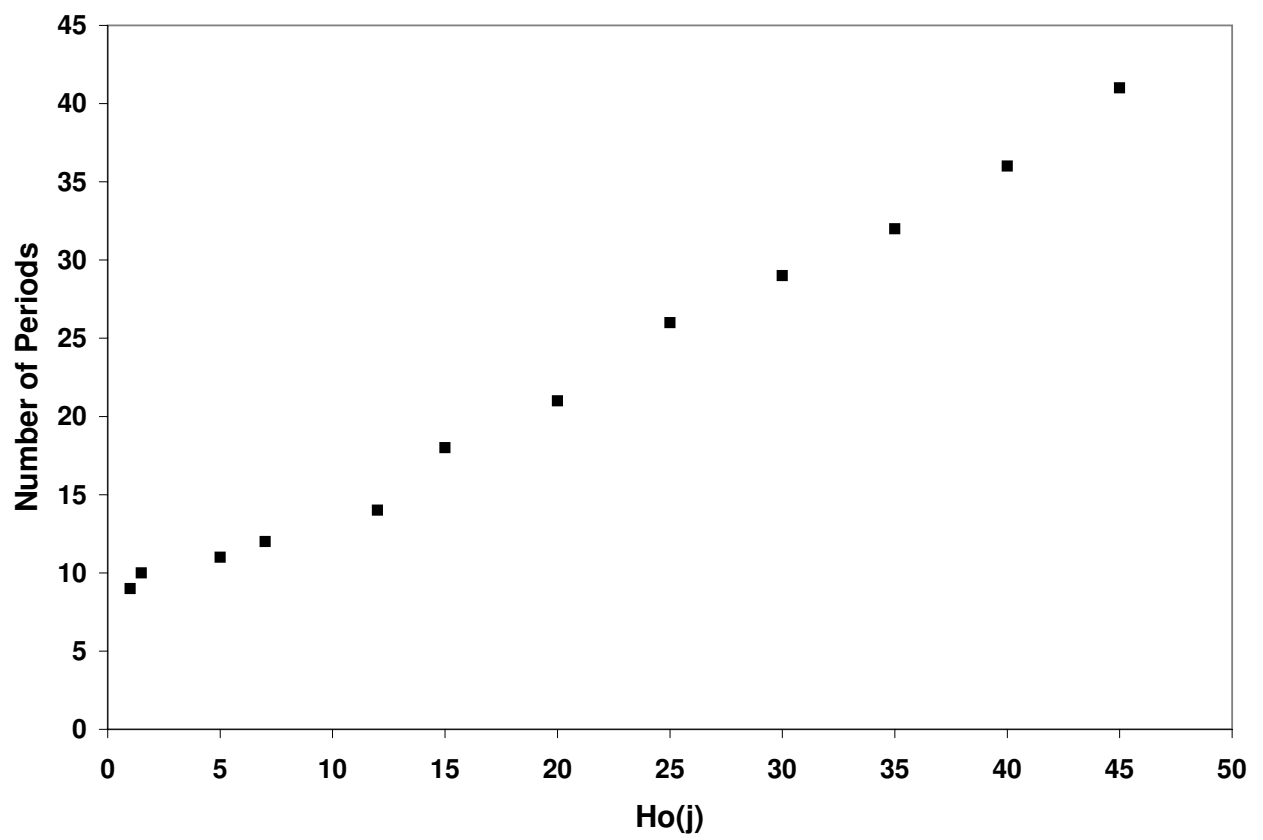

Figure 8:

Model Simulation: Transition from $5 \%$ to $50 \%$ of Max. Exports

weight not only to what they see as their new car but also to their previously held beliefs. This occurs because certain attributes of a car, like its durability, are difficult, if not impossible, to immediately detect. Over time, these beliefs change as the car is used. An example of a sector associated with rapid learning and reputation processes is the agricultural goods sector. Consumers can easily inspect and discern the nature of the good by tasting the food or beverage, updating their beliefs immediately.

In our model, we capture the learning and reputation process associated with a sector $j$ by the initial ratio of the precision of the importers' beliefs to the precision of the idiosyncratic productivity shock, $H_{0}(j)=\frac{h_{\hat{\eta}_{i 0}}(j)}{h_{\epsilon}(j)}$, where $H_{0}(j) \in(0, \infty)$. As a result, when using equation $(5)$ to update their beliefs for the next period, importers attach weights $h_{\hat{\eta}_{i 0}}(j)$ and $h_{\epsilon}(j)$ to their prior beliefs and the exporter's signal, respectively. $H_{0}(j)=1$ corresponds to the case when importers attach equal weights to their prior beliefs and the exporter's signal, while $H_{0}(j)>1\left(H_{0}(j)<1\right)$ corresponds to when importers attach relatively more (less) weight to their prior beliefs.

Sectors in which importers place relatively more weight, $h_{\hat{\eta}_{i 0}}(j)$, on their prior beliefs are those with a relatively high $H_{0}(j)$. Learning and reputation building occur relatively slowly over time in these sectors, as in the car example above. Sectors in which importers place relatively less weight, $h_{\hat{\eta}_{i 0}}(j)$, on their prior beliefs are those with a relatively low $H_{0}(j)$. Learning and reputation building occur relatively faster in these sectors, as in the agricultural goods example above.

Figure 8 shows how the model's predicted trade patterns change with changes in $H_{0}$. The higher 
$H_{0}$ is, the slower is the increase in total exports. Figure 8 reports one measure capturing the difference in the speed at which total exports increase, namely the number of periods required to transition from $5 \%$ to $50 \%$ of the maximum level of total exports.

\subsection{Information and Trade Policies}

We now extend the basic model from section 2 to incorporate trade barriers and export subsidies. In addition to the traditional increase or decrease in the volume of trade, our model highlights another dimension of trade barriers and export subsidies, namely their effect on the extent of asymmetric information existing between importers and exporters.

In order to measure the extent of these information problems in our model, we need to identify the relation between importers' beliefs and exporters' true characteristics. After the realization of output at the end of time $t, \frac{y_{i t}}{\phi_{i t}}=\kappa_{i t}$, which potentially may be different than $1 . \kappa_{i t}$ can be interpreted as a measure of informational problems among importers and exporter $i$ at time $t$. The further $\kappa_{i t}$ is from 1 , the more information problems there are between importers and exporter $i . \kappa_{i t}>1$ corresponds to the case when importers undervalue exporter $i . \kappa_{i t}<1$ corresponds to the case when importers overvalue exporter $i . \kappa_{i t}$ is an important dimension in international trade which we study under three different trade policy regimes: trade barriers, export subsidies, and free trade with no export subsidies.

Among other things, trade barriers can be thought of as import tariffs or transportation costs, the former incurred by importers and the latter incurred by exporters. In the context of our model, we view these trade barriers as a friction which reduces the offer received by an exporter. In the case of an import tariff, importers pay some share of their offer $\phi_{i t}$ as a tariff. The importers' new offers including the tariff payment can be denoted as $\tilde{\phi}_{i t}$ and will necessarily be lower than $\phi_{i t} .{ }^{20}$ In the case of transportation costs, exporters pay some amount from $\phi_{i t}$ to ship their goods to the home country, hence the portion left over as profit can be denoted $\tilde{\phi}_{i t}$. Instead of drawing a distinction between these two types of trade barriers, we simply model trade barriers as some fixed payment, $\psi$, taken from $\phi_{i t}$.

Government export subsidies can also be used to affect trade patterns and the extent of asymmetric information between importers and exporters. We do not explicitly model a government's problem in this section but consider export subsidies exogenously available to the foreign country exporters. In terms of the exporter's problem, an export subsidy can be modeled as a fixed amount, $\psi$, subtracted from the exporter's cost of exporting, $c_{i t}$. We can then denote the cost of exporting under an export subsidy as $\tilde{c}_{i t}$, which is necessarily lower than $c_{i t}$.

\footnotetext{
${ }^{20}$ Recall that importers' optimal offers without tariffs at time $t$ for each exporter $i$ is given by equation (4).
} 


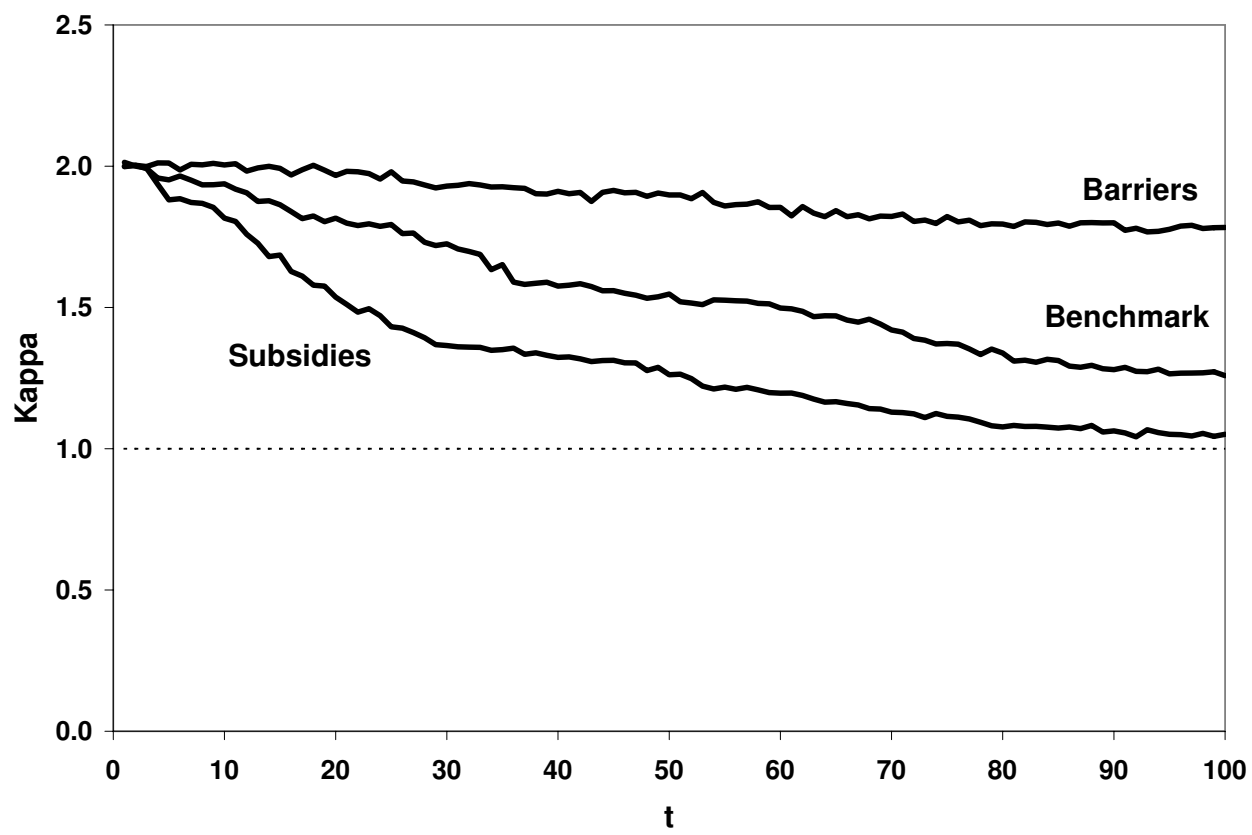

Figure 9:

Model Simulation: Kappa, Different Trade Policies

Figure 9 compares the informational environment under the three different policy regimes by reporting the $\kappa$ 's associated with each regime. Figure 9 reports an average aggregate measure of $\kappa$. Trade barriers increase information problems, since it is more difficult for exporters to enter the market to begin with. Export subsidies, however, decrease the informational problems between importers and exporters. To the best of our knowledge, this is not an aspect of export subsidies which is often considered when discussing policy implications.

\section{Conclusion}

We have attempted to enrich the study of international trade theory by developing a framework which casts asymmetric information, learning, and reputation as the leading roles. In our framework, international trade takes place when exporters accept belief-based offers from importers in exchange for shipments of exporters' goods. Importers then update their beliefs according to signals derived from the arrival of the exporters' goods. These new beliefs determine the new offers made to exporters and, consequently, affect the subsequent decision of whether to export. As a result, learning and reputation building change the informational environment in which importers and exporters interact and, thus, have a direct effect on the determination of international trade patterns.

The most obvious, yet important, implication of our framework for the study of international trade 
is that a firm's ability to export depends not only on its characteristics but also on what importers believe about those characteristics. The history of Japanese car exports to the U.S. reflects this main idea. Existing literature and available evidence create a compelling case for asymmetric information, learning, and reputation to be at the heart of any explanation of Japanese car imports. We show our model is capable of replicating the experience of U.S. car imports from Japan over the period 1961-2005.

In addition to deepening our understanding of these events, we discuss further implications of our framework. Since learning and reputation building require time, our model forces us to also take seriously the difference in short run and long run trade patterns. The long run results of our model match those of Melitz (2003), but the short run results can be quite different. We show how sectorial differences in the speed of learning and reputation building affect predicted trade patterns. The extent of asymmetric information existing between importers and exporters also changes under different trade policies, and we compare the free trade, trade barrier, and export subsidy cases of our model. 


\section{Appendix}

\section{Appendix A: Proofs of Lemma 1 and Propositions 1 and 2}

\section{Proof of Lemma 1:}

The offer (4) and learning (5) equations together imply that offers at time $t+1$ are strictly increasing in the amount of $y$ exported at time $t$. Clearly, profit is strictly increasing in the offer (and recall that $f$ is independent of $y$ ). Finally, the exporter's objective function is strictly increasing in profits. Taken together, these imply $y_{i t}=\eta_{i}+\epsilon_{i t}$ under the decision to accept.

\section{Proof of Proposition 1:}

The sequential version of the exporter's problem can be written as follows: For $t=\tau$, given Lemma 1, the offer (4), and the learning process (5) and (6), an exporter $i$ solves $\max \left\{A_{i \tau}, R_{i \tau}\right\}$ subject to the constraints $A_{i \tau}=\pi_{i \tau}\left(y_{i}^{\tau-1}\right)+\beta E_{\tau}\left[\pi_{i \tau+1}\left(y_{i}^{\tau}\right)\right]+\ldots, R_{i \tau}=0+\beta E_{\tau}\left[\hat{\pi}_{i \tau+1}\left(\hat{y}_{i}^{\tau}\right)\right]+\ldots$, and also subject to nonnegative profits for every period. Profits in the case when an exporter accepts are $\pi_{i t}\left(y_{i}^{t-1}\right)=\phi_{i t}\left(y_{i}^{t-1}\right)-c_{i t}$. In the case when an exporter rejects, profits are $\pi_{i t}\left(y_{i}^{t-1}\right)=0 .{ }^{21}$ Similarly, the cost of exporting when an exporter accepts is given by $c_{i t}=f-u_{i t}$. When an exporter rejects, $c_{i t}=0$. At $t=\tau$, an exporter $i$ chooses whether to accept or reject given the offer (beliefs of importers) and realized shocks $(\epsilon, u)$. $A$ and $R$ are the expected discounted lifetime profit streams in the cases of accepting and rejecting. $\pi$ and $\hat{\pi}$ refer to the profits in the cases of accepting and rejecting. Since the exporter solves the problem at $t=\tau$ conditional on the information at $\tau$, expectations are conditional on $\tau$.

Given the problem above, we define $u_{\pi_{i t=0}}$ as the threshold for zero profits at time $t$. If $u_{i t} \geq u_{\pi_{i t=0}}$, then $\pi_{i t} \geq 0$, and if $u_{i t}<u_{\pi_{i t=0}}$, then $\pi_{i t}<0$. Given the offer and $f, u_{\pi_{i t=0}}$ can be obtained from $\pi_{i t}\left(y_{i}^{t-1}\right)=\phi_{i t}\left(y_{i}^{t-1}\right)-f+u_{i t} . \underline{\epsilon}_{i t}$ is the threshold productivity shock defined by the following: if $\epsilon_{i t} \geq \underline{\epsilon}_{i t}$, then $A \geq R$, and if $\epsilon_{i t}<\underline{\epsilon}_{i t}$, then $A<R$.

There are potentially four different cases. We first summarize the results of the different cases and then prove the results in the remainder of the appendix. For both of the cases when $u_{i t}<u_{\pi_{i t=0}}$, the nonnegative profit constraint binds, and exporter $i$ rejects the offer. ${ }^{22}$ For the case $u_{\pi_{i t=0}}<u_{i t}$ and $\underline{\epsilon}_{i t} \leq \epsilon_{i t}$, exporter $i$ realizes nonnegative profits during the current period and anticipates a higher expected discounted lifetime profit stream from accepting compared to rejecting. As a result, exporter $i$ accepts the offer in this case. In the last case, $u_{\pi_{i t=0}}<u_{i t}$ and $\underline{\epsilon}_{i t}>\epsilon_{i t}$, exporter $i$ has nonnegative

\footnotetext{
${ }^{21}$ We suppress $y_{i}^{t-1}$ from now on.

${ }^{22}$ Specifically, the first case is $u_{i t}<u_{\pi_{i t=0}}$ and $\underline{\epsilon}_{i t}<\epsilon_{i t}$, and the second case is $u_{i t}<u_{\pi_{i t=0}}$ and $\underline{\epsilon}_{i t} \geq \epsilon_{i t}$.
} 


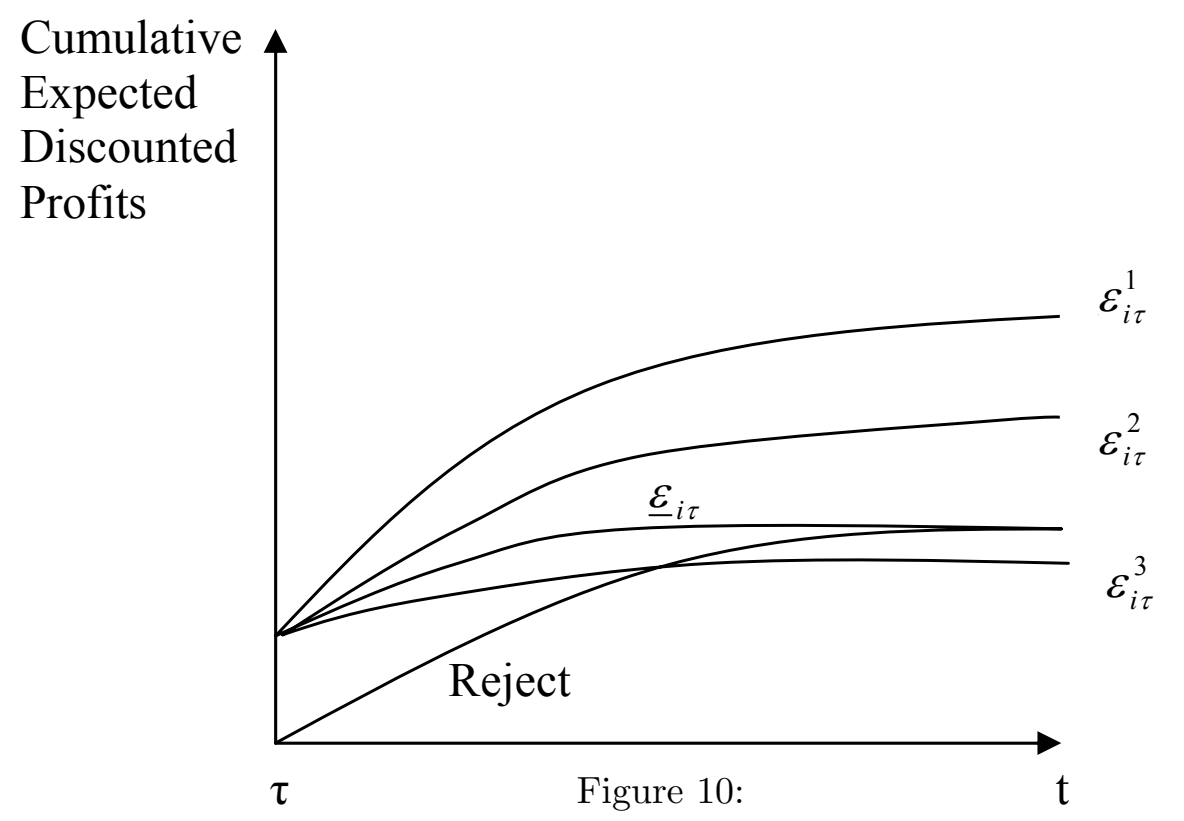

Cumulative Expected Discounted Profits Under Different $\epsilon_{i \tau}$ 's

profits during the current period, but the expected discounted lifetime profit stream from accepting will be lower than that from rejecting. Intuitively, an exporter $i$ can make nonnegative profits by accepting the offer but will affect its reputation in such a way that the current gain from profits will not compensate the future loss caused by a bad reputation. Exporter $i$ rejects the offer in this case.

In order for the decision of accepting to be optimal, two conditions have to be satisfied at time $\tau$. First, clearly, the nonnegativity condition for profits, $\pi_{i \tau} \geq 0$, must hold. Second, the R.H.S. of the following equation also has to be greater than or equal to the L.H.S. (i.e. $R \leq A$ ):

$$
\underbrace{0+\beta \cdot E_{\tau}\left[\hat{\pi}_{i \tau+1}\right]+\beta^{2} \cdot E_{\tau}\left[\hat{\pi}_{i \tau+2}\right]+\ldots}_{R} \lesseqgtr \underbrace{\pi_{i \tau}+\beta \cdot E_{\tau}\left[\pi_{i \tau+1}\right]+\beta^{2} \cdot E_{t}\left[\pi_{i \tau+2}\right]+\ldots}_{A}
$$

Given the fixed parameters, realized $u_{i \tau}$, and an offer at time $\tau, \epsilon_{i \tau}$ determines whether the R.H.S. or L.H.S. of (A.1) is greater. The R.H.S. of equation (A.1) is strictly increasing in $\epsilon_{i \tau}$, and the L.H.S. is independent of $\epsilon_{i \tau}$. Hence, there exists a unique $\epsilon_{i \tau}$ which equates L.H.S and R.H.S..

Figure 10 shows the curves for the cumulative expected discounted profit across time under different $\epsilon_{i \tau}$ 's. The final end points of the curves correspond to the finite values of the expected discounted lifetime profit streams. In figure $10, \epsilon_{i \tau}^{1}>\epsilon_{i \tau}^{2}>\underline{\epsilon}_{i \tau}>\epsilon_{i \tau}^{3}$.

Now, let's look at why the R.H.S. is strictly increasing in $\epsilon_{i \tau}$. A higher $\epsilon_{i \tau}$ corresponds to a higher $y_{i \tau}$, which means, by equation (5), higher $\epsilon_{i \tau}$ 's correspond to a higher offer at time $\tau+1$. As a result, a higher $\epsilon_{i \tau}$ corresponds to a higher expected discounted profit at time $\tau+1$. Moreover, a higher offer in expected terms at time $\tau+1$ corresponds to a higher offer at time $\tau+2$ in expected terms. As a result, a higher $\epsilon_{i \tau}$ also corresponds to a higher expected discounted profit at time $\tau+2$. The same reasoning holds for future periods. Hence, this result shows that a higher $\epsilon_{i \tau}$ corresponds to a higher cumulative 
expected discounted profit curve in figure 10. Notice that all curves begin at the same value on the $\mathrm{y}$-axis in the case of accepting, since $\epsilon_{i \tau}$ does not affect the profit at time $\tau$. The curve corresponding to $\epsilon_{i \tau}^{1}$ is higher than that corresponding to $\epsilon_{i \tau}^{2}$. As $\epsilon_{i \tau}$ becomes lower, the corresponding curve lowers in figure 10 as well. At some point, the curve corresponding to $\epsilon_{i \tau}$, which we denote $\underline{\epsilon}_{i \tau}$, converges to the reject curve. Recall that the reject curve is independent of $\epsilon_{i \tau} \cdot \underline{\epsilon}_{i \tau}$ makes equation (A.1) hold with equality.

$\epsilon_{i \tau}^{3}$, which is lower than the threshold, $\underline{\epsilon}_{i \tau}$, makes the R.H.S. less than the L.H.S. in equation (A.1). The curve corresponding to $\epsilon_{i \tau}^{3}$ shows the acceptance (notice that acceptance is not optimal) case in which $\epsilon_{i \tau}<\underline{\epsilon}_{i \tau}$. Under this condition, current profits at time $\tau$, seen in figure 10 as the intersection with the y-axis, are greater than zero for $\epsilon_{i \tau}^{3}$ and equal to zero for the reject curve. At some point, the reject curve crosses the $\epsilon_{i \tau}^{3}$ curve and remains above thereafter. At time $\tau+n$, at which point the reject curve crosses the $\epsilon_{i \tau}^{3}$ curve, the expected offer for the reject case has to be greater than the expected offer for the acceptance case. This guarantees the reject curve remains above the $\epsilon_{i \tau}^{3}$ curve by the same reasoning in the previous case above. Since the reject curve converges to a higher value than the $\epsilon_{i \tau}^{3}$ curve (i.e. higher expected discounted lifetime profit), rejecting is the optimal decision for exporter $i$ in the case in which $u_{\pi_{i t} \geq 0}<u_{i t}$ and $\underline{\epsilon}_{i t}>\epsilon_{i t}$. Similarly, for the case when $\pi_{i \tau} \geq 0$ and $\epsilon_{i \tau} \geq \underline{\epsilon}_{i \tau}$, accepting and exporting is optimal, because the discounted expected lifetime profit is greater than that when rejecting.

\section{Proof of Proposition 2:}

To prove proposition 2, we already know that given the offer and the fixed parameters, including the realized $u_{i \tau}$, there exists a threshold $\epsilon_{i \tau}$ which equates equation (A.1). Fixing other parameters constant, increasing the mean of the beliefs, $\mu_{\eta_{i \tau}}$, at time $\tau$, increases the R.H.S. more than the L.H.S. at time $\tau$. Since the L.H.S. is independent of $\epsilon_{i \tau}$ and the R.H.S. is strictly increasing in $\epsilon_{i \tau}$, the new threshold equating equation (A.1) is smaller.

\section{Appendix B: Numerical Simulations}

This section explains the details of the simulations in section 4 and presents the parameters used in each simulation. In all the simulations, there is a set of benchmark parameters with which to compare different situations. The benchmark case will be compared with overvalued beliefs (figure 6 from section 4.1), under different $H_{0}$ 's (figure 8 from section 4.2), and with trade barriers and export subsidies (figure 9 from section 4.3).

For the benchmark case, the number of time periods is set to $T=100$ in order to show the potential 
differences in the short and long run. We set the potential number of exporters to $I=15$, where the number of actual exporters is determined endogenously. We choose the discount factor $\beta=0.99$. The parameters of the prior belief distribution are $\mu_{\hat{\eta}_{0}}=1000$ and $\sigma_{\hat{\eta}_{0}}=100$. We set the actual productivity to $\eta=2000$. For simplification, all the exporters have the same actual productivity level, $\eta$, which can be interpreted as a normalization. Note that the benchmark case corresponds to the case where importers undervalue exporters. Posterior beliefs are determined endogenously. We set the parameters for productivity shocks and cost shocks to be the same: $\mu_{\epsilon}=\mu_{c}=0$ and $\sigma_{\epsilon}=\sigma_{u}=100$. As a result of this parametrization, $H=1$ in the benchmark case, i.e. importers give equal weight to their beliefs and their experience in each period. Finally, the parameter of the cost function is set to $f=1300$.

In the first simulation (figure 6), we compare two cases, one in which importers undervalue exporters (benchmark) and another in which importers overvalue exporters. We choose two opposite examples of importers' beliefs in order to highlight the effect of asymmetric information and the importance of learning, reputation building, and signaling. The parameters of the benchmark case are described above. For the case when importers overvalue exporters, we just change the parameters $\mu_{\hat{\eta}_{0}}$ and $\eta$ and keep all the other parameters the same. We set $\mu_{\hat{\eta}_{0}}=2000$ and $\eta=1200$. We run the simulations 10000 times and present the average values of these simulations in figure 6 .

In the second simulation (figure 8 ), we compare different $H_{0}$ 's, fixing all the other parameters to be the same as the parameters in the benchmark case above. We let $H_{0} \in[1,45]$ to show the results under different values for $H_{0}$. We change the precision of the prior beliefs, $h_{\hat{\eta}_{i 0}}$, in order to get different values of $H_{0}$ in the simulations. Again, we run the simulations 10000 times and present the average values.

In the third simulation (figure 9), we compare the benchmark case with two other cases. The first case is the one with trade barriers, and the second case is the one with export subsidies. The benchmark case can be interpreted as free trade with no export subsidy policies. In the trade barriers case, $\psi=+50$ and all the remaining parameters are the same. Recall, $\psi=0$ corresponds to the benchmark case. In the export subsidies case, $\psi=-50$ and, again, all the other parameters are the same as those in the benchmark case. Figure 9 shows how the extent of asymmetric information, $\kappa$, changes under different policy regimes. We take the average over $I$ exporters in a given simulation, and, then, we run the simulations 10000 times and present the average values over the simulations. Since we run the simulations 10000 times, the effects of productivity shocks are washed out of $\kappa$. 


\section{References}

Akerlof, G. A. (1970): "The Market for "Lemons": Quality Uncertainty and the Market Mechanism," Quarterly Journal of Economics, 84(3), 488-500.

Bradsher, K. (2007): “Toyota Tops G.M. in Sales for First Time," New York Times, p. April 24.

Crandall, R. W., and C. Winston (2005): "Auto Industry on the Line," Detroit Free Press, p. May 23.

Falvey, R. E. (1989): “Trade, Quality Reputations and Commerical Policy," International Economic Review, 30(3), 607-622.

Gertner, J. (2007): "From 0 to 60 to World Domination," New York Times, p. February 18.

Gould, D. M. (1994): "Immigrant Links to the Home Country: Empirical Implications for U.S. Bilateral Trade Flows," Review of Economics and Statistics, 76(2), 302-316.

Greif, A. (1989): "Reputation and Coalitions in Medieval Trade: Evidence on the Maghribi Traders," Journal of Economic History, 49(4), 857-882.

Guiso, L., P. Sapienza, And L. Zingales (2009): “Cultural Biases in Economic Exchange?," Quarterly Journal of Economics, 124(3), 1095-1131.

Holmstrom, B. (1999): "Managerial Incentive Problems: A Dynamic Perspective," Review of Economic Studies, 66(1), 169-182.

Mannering, F., And C. Winston (1991): "Brand Loyalty and the Decline of American Automobile Firms," Brookings Papers on Economic Activity: Microeconomics, pp. 67-114.

Melitz, M. J. (2003): "The Impact of Trade on Intra-Industry Reallocations and Aggregate Industry Productivity," Econometrica, 71(6), 1695-1725.

Nieuwerburgh, S. V., and L. Veldkamp (2009): "Information Immobility and the Home Bias Puzzle," Journal of Finance, 64(3), 1187-1215.

Rauch, J. E., And V. Trindade (2002): "Ethnic Chinese Networks in International Trade," Review of Economics and Statistics, 84(1), 116-130. 
Shapiro, C. (1983): "Premiums for High Quality Products as Returns to Reputations," Quarterly Journal of Economics, 98(4), 659-680.

Spence, M. (1973): "Job Market Signaling," Quarterly Journal of Economics, 87(3), 355-374.

TAdelis, S. (1999): "What's in a Name? Reputation as a Tradeable Asset," American Economic Review, 89(3), 548-563.

Train, K. E., and C. Winston (2007): "Vehicle Choice Behavior and the Declining Market Share of U.S. Automakers," International Economic Review, 48(4), 1469-1496.

WoJcIK, C. (2001): "Learning by Consumers in the Demand for Japanese Cars," Review of International Economics, 9(1), 94-107. 